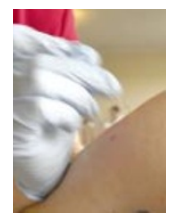

Sharp rebuke

Biodefence scientists make disputed claims for smallpox vaccine p332

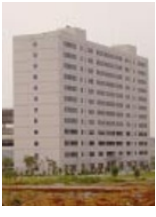

\section{High hopes}

New Chinese agency aims to transform biomedical research p333

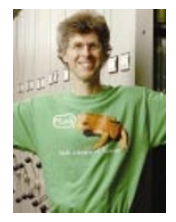
Access denied

Paper ignites row with journal over open access p334

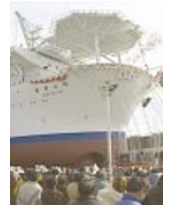
Sail on

Ocean drilling project relaunched on international waters p337

\title{
Gates steps up war on malaria with donation of \$168 million
}

Declan Butler, Manhica, Mozambique

Bill and Melinda Gates, the world's richest couple, are to make the biggest-ever single donation to malaria research.

The Bill and Melinda Gates Foundation, which has an endowment of $\$ 25$ billion, is to provide a \$168-million block of grants for various treatment and vaccination strategies. It has already donated more than $\$ 3$ billion to global health research.

The philanthropists made the announcement on a visit to Mozambique last weekend, at the Manhica Health Research Centre 80 kilometres north of the capital, Maputo, accompanied by the prime minister Pascoal Mocumbi. Earlier, the couple held children - some of them suffering from cerebral malaria - taking part in the largest clinical trial of a malaria vaccine.

Bill Gates said that their trip to Africa, which included visits to South Africa and Botswana to discuss AIDs-related issues, was to raise awareness of the need for more research into malaria. The disease infects almost half a billion people and kills more than a million annually, mostly young children in Africa. The resurgence of malaria in Africa is partly a result of increased resistance to common antimalarial drugs.

Current spending on malaria control is $\$ 200$ million a year, far short of the $\$ 2.5$ billion a year that the WHO Commission on Macroeconomics and Health estimates is needed.

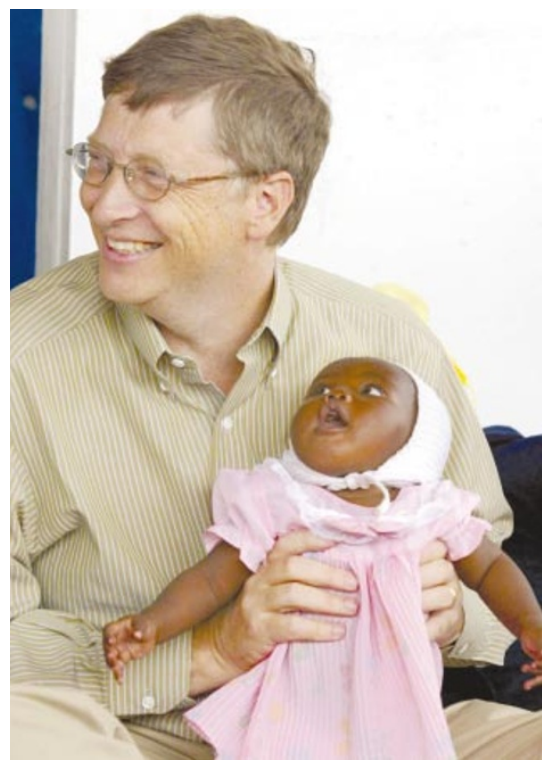

Safe hands: Bill Gates with baby Cecil Massango.

Total annual research spending on malaria is just $\$ 100$ million. Not everything will be solved by his money, says Gates, adding that his emphasis is to bridge the gap between basic research and industrial development.

Of the new grants, $\$ 28$ million over five years will fund an international consortium to test as quickly as possible a promising new control technique known as intermittent preventive treatment'. Two years ago researchers reported that incidence of severe malaria was halved in infants who were given an antimalarial drug three times during their first year of life, when they attend routine immunization sessions (D. Schellenberg etal. Lancet 357, 1471-1477; 2001). The natural immunity built up by infected children was not impaired by the treatment.

Richard Klausner, head of the foundation's global health activities, says that the observations are scientifically fascinating. "The children continue to show the memory of being given treatment," he says, as if the drug were almost working as a vaccine. Fifteen studies in nine countries will now explore this further, with a view to rapid implementation if it works.

The public-private drug-development partnership Medicines for Malaria Venture, of Geneva, will receive $\$ 40$ million to accelerate development of the four most advanced drugs in its 21-candidate pipeline. Its goal is for at least one new antimalarial drug to be licensed by the end of the decade.

The Seattle-based Malaria Vaccine Initiative is awarded $\$ 100$ million over four years to speed clinical trials of its 15 candidates.

The foundation is discussing grants for a malaria postgenomics programme with the US National Institutes of Health and the UK Wellcome Trust, Klausner adds, and envisages grants for mosquito-vector research.

\section{UK public opposes government on transgenic crops}

\section{Jim Giles, London}

The British government, set to rule on the legalization of genetically modified (GM) crops, is in a corner after a study that it commissioned confirmed deep-seated concern among the public.

Although the government is believed to want to allow transgenic crops to be grown in Britain, it will find the negative report hard to ignore, in part because of recent accusations that it ignored public opinion over its decision to go to war with Iraq.
The results of this summer's 'GM Nation?' debate, a series of some 670 public meetings that attracted up to 20,000 participants, reveal a British public uneasy with the potential environmental, health and socio-economic effects of transgenic crops. More than half the participants who returned feedback forms after the debate said they never wanted to see GM crops grown in Britain, according to a report due to be released on 24 September.

The government commissioned the exercise to help it decide whether to give the go-ahead for commercialization of transgenic crops. Britain, along with other European Union countries, will begin voting later this year on whether to license some 15 new varieties of transgenic crop, ending a five-year moratorium on new approvals.

Industry representatives say that the results of the debate were skewed by the presence of environmental activists at the meetings, but the result may still put pressure on the government. 